\title{
Periodic Sequence Distribution of Product Ion Abundances in Electron Capture Dissociation of Amphipathic Peptides and Proteins
}

\author{
Hisham Ben Hamidane, ${ }^{a}$ Huan He, ${ }^{\mathrm{b}, \mathrm{c}}$ Oleg Yu. Tsybin, ${ }^{\mathrm{d}}$ \\ Mark R. Emmett, ${ }^{b, c}$ Christopher L. Hendrickson, ${ }^{b, c}$ Alan G. Marshall, b,c \\ and Yury O. Tsybin ${ }^{\mathrm{a}}$ \\ a Biomolecular Mass Spectrometry Laboratory, Ecole Polytechnique Fédérale de Lausanne, Lausanne, Switzerland \\ b Ion Cyclotron Resonance Program, National High Magnetic Field Laboratory, Florida State University, \\ Tallahassee, Florida, USA \\ ${ }^{c}$ Department of Chemistry and Biochemistry, Florida State University, Tallahassee, Florida, USA \\ d Ion Physics Laboratory, Radiophysics Faculty, State Polytechnical University, Saint-Petersburg, Russia
}

The rules for product ion formation in electron capture dissociation (ECD) mass spectrometry of peptides and proteins remain unclear. Random backbone cleavage probability and the nonspecific nature of ECD toward amino acid sequence have been reported, contrary to preferential channels of fragmentation in slow heating-based tandem mass spectrometry. Here we demonstrate that for amphipathic peptides and proteins, modulation of ECD product ion abundance (PIA) along the sequence is pronounced. Moreover, because of the specific primary (and presumably secondary) structure of amphipathic peptides, PIA in ECD demonstrates a clear and reproducible periodic sequence distribution. On the one hand, the period of ECD PIA corresponds to periodic distribution of spatially separated hydrophobic and hydrophilic domains within the peptide primary sequence. On the other hand, the same period correlates with secondary structure units, such as $\alpha$-helical turns, known for solution-phase structure. Based on a number of examples, we formulate a set of characteristic features for ECD of amphipathic peptides and proteins: (1) periodic distribution of PIA is observed and is reproducible in a wide range of ECD parameters and on different experimental platforms; (2) local maxima of PIA are not necessarily located near the charged site; (3) ion activation before ECD not only extends product ion sequence coverage but also preserves ion yield modulation; (4) the most efficient cleavage (e.g. global maximum of ECD PIA distribution) can be remote from the charged site; (5) the number and location of PIA maxima correlate with amino acid hydrophobicity maxima generally to within a single amino acid displacement; and (6) preferential cleavage sites follow a selected hydrogen spine in an $\alpha$-helical peptide segment. Presently proposed novel insights into ECD behavior are important for advancing understanding of the ECD mechanism, particularly the role of peptide sequence on PIA. An improved ECD model could facilitate protein sequencing and improve identification of unknown proteins in proteomics technologies. In structural biology, the periodic/preferential product ion yield in ECD of $\alpha$-helical structures potentially opens the way toward de novo site-specific secondary structure determination of peptides and proteins in the gas phase and its correlation with solution-phase structure. (J Am Soc Mass Spectrom 2009, 20, 1182-1192) (c) 2009 Published by Elsevier Inc. on behalf of American Society for Mass Spectrometry

$\mathrm{B}$ iomolecular fragmentation in the gas phase by electron capture dissociation (ECD) [1-3] and electron-transfer dissociation (ETD) $[4,5]$ is particularly attractive for mass spectrometry (MS)-based peptide and protein structural analysis. In ECD/ETD, interaction of a multiply charged peptide or protein ion with an electron/anion results in cleavage of $\mathrm{N}-\mathrm{C}_{\alpha}$ bonds along the peptide backbone, including chargesite-remote backbone cleavages [2]. ECD is useful for

Address reprint requests to Prof. Dr. Yury O. Tsybin, Ecole Polytechnique Fédérale de Lausanne (EPFL), Biomolecular Mass Spectrometry Laboratory, Institute of Chemistry and Chemical Engineering, BCH 4307, 1015 Lausanne, Switzerland. E-mail: yury.tsybin@epfl.ch peptide sequence tag generation on a chromatographic timescale for protein identification in bottom-up mass spectrometry [6], de novo peptide sequencing [7], recognition of amino acid chirality [8], location and structural determination of single and multiple posttranslational modifications (PTMs) in peptides $[9,10]$, sequencing and PTM analysis of large proteins (up to $50-60 \mathrm{kDa}$ ) [11], and providing insight into protein secondary and tertiary structures in the gas phase [12, 13]. ETD has already demonstrated high potential in several ECD application areas and continues to gain attention in peptide and protein structural analysis, especially in (phospho)proteomics [5, 14, 15].
(C) 2009 Published by Elsevier Inc. on behalf of American Society for Mass Spectrometry. 1044-0305/09/\$32.00

doi:10.1016/j.jasms.2009.02.015
Published online February 13, 2009 Received December 6, 2008 Revised January 14, 2009 Accepted February 8, 2009 
Revealing the influence of amino acid distribution and other precursor ion properties, such as number and location of charges, on ECD product ion formation has improved the fundamental understanding of ion-electron and ion-ion reactions [13, 16-18] and demonstrates potential toward practical utility $[19,20]$. ECD is generally less specific than collision-induced dissociation (CID) and is reported not to have a significant preference toward any, except $\mathrm{S}-\mathrm{S}$, bond cleavage. As a result, fragmentation of a number of peptides studied since first ECD implementation in 1998 has not revealed a structured pattern or a direct correlation with single amino acid properties $[16,20]$. Nevertheless, product ion abundance (PIA) distribution in ECD of peptides is believed to depend on peptide secondary structure in the gas phase [13]. Recent experimental and theoretical progress confirms the important role of hydrogen bonds in the backbone cleavage mechanism [21], allows better prediction of ECD product ion distribution [22-24], and establishes correlation with gas-phase peptide and protein structures $[12,25,26]$. However, the high structural complexity of peptides and proteins limits computational capabilities [21] and complicates analysis of the experimental results. Advances in ECD/ETD applications have been accompanied by development of an array of other MS-based techniques and methods to address specific peptide and protein conformation-induced effects. In particular, ion mobility mass spectrometry (IM MS) has been used for targeted and high-throughput characterization of $\alpha$-helical peptide properties in the gas phase [27-29]. The combination of mass spectrometry with gas-phase ultraviolet/infrared (UV/IR) spectroscopy has provided evidence for helical structure in gaseous protein ions [30] and poly-Ala peptides [31]. Collision-induced dissociation of peptide cations in the gas phase has been linked to peptide structure stability and secondary structure elements [32, 33].

Understanding of peptide sequence and structure effects on fragmentation in tandem mass spectrometry (MS/MS) can be facilitated by selection of a class of biomolecules of interest with well-defined structural properties. In general, amino acids have strong positiondependent probabilities of appearance in $\alpha$-helical or $\beta$-strand peptides and proteins [34]. Amphipathic peptides are those that exhibit a periodic (typically every 3 to 4 residues) distribution of hydrophobic and hydrophilic amino acids along the peptide backbone [35]. The characteristic amino acid distribution in amphipathic peptides results in formation of two opposite faces: hydrophobic and hydrophilic. Among a variety of different secondary structures formed by spatially segregated hydrophobic and hydrophilic regions upon peptide folding, amphipathic $\alpha$-helices occur most frequently. Therefore, we selected the class of amphipathic peptides and proteins to probe ECD characteristics, to improve both fundamental and practical aspects of ECD in MS/MS. Projection of ECD Fourier transform ion cyclotron resonance (FT-ICR) MS results to ETD in ion trap MS is considered as a second step and will require estimation of ion cooling at the higher pressure of ETD experiments [36].

As discussed in the following text, ECD FT-ICR MS applied to amphipathic peptides and proteins demonstrates a striking periodic sequence variation in ECD PIA. We first describe periodic ECD PIA extending over several turns of an $\alpha$-helical transmembrane domain (M2 transmembrane peptide [TMP]), of the influenza virus A membrane protein M2. We then extend investigation of periodic sequence distribution of ECD PIA for various amphipathic peptides and proteins. As a summary, we compile a set of general rules for ECD of amphipathic peptides and proteins. Finally, we briefly elaborate on the possible influence of peptide primary and secondary structures on ECD PIA.

\section{Experimental}

\section{Sample Preparation}

Standard peptides and proteins were obtained from Sigma-Aldrich (St. Louis, MO, USA), American Peptide Company, or synthesized by fluorenylmethyloxycarbonyl (Fmoc) solid-phase peptide synthesis (Peptide and Protein Synthesis Facility, University of Lausanne, Switzerland) and used without further purification. Peptides were dissolved in water and acetonitrile (50: 50 , vol/vol) with addition of $0.1 \%$ formic acid. A myoglobin digest was performed with trypsin and Asp-N following a standard procedure [37]. Tryptic digestion was performed with $50 \mu \mathrm{L}$ containing $1 \mathrm{nM}$ myoglobin and $\sim 35.5 \mathrm{pM}$ trypsin in $50 \mathrm{mM}\left(\mathrm{NH}_{4}\right)_{2} \mathrm{CO}_{3}$ buffer ( $\mathrm{pH} 8.0)$ at 1:20 enzyme:protein ratio by weight. Asp-N digestion was performed with $50 \mu \mathrm{L}$ containing $1 \mathrm{nM}$ myoglobin and $12.5 \mathrm{pM}$ Asp-N in $50 \mathrm{mM}$ sodium phosphate buffer $(\mathrm{pH} 8.0)$ at 1:50 enzyme: protein ratio by weight. Formic acid was added to acidify the solution and stop digestion after sample incubation at about $37^{\circ} \mathrm{C}$ overnight [37]. Mixtures of enzymatic peptides were HPLC purified before sample preparation for electrospray ionization. The wild-type transmembrane domain M2 TMP samples were obtained in collaboration with the NMR Program, National High Magnetic Field Laboratory, Tallahassee, FL (Dr. T. A. Cross). Antimicrobial peptides, piscidin 1 and piscidin 3 , in amide and free acid forms were obtained through collaboration with Dr. Myriam L. Cotten (Pacific Lutheran University, Tacoma, WA).

\section{Tandem Mass Spectrometry}

Electron capture dissociation (ECD) and activated ion (AI)-ECD experiments were performed with a previously described 9.4 T FT-ICR mass spectrometer [3840] and a recently installed hybrid 12 T LTQ FT-ICR MS (Thermo Fisher Scientific, Bremen, Germany). Either Nanomate or TriVersa electrospray ion source interfaces (Advion Biosciences, Ithaca, NY, USA) were used to generate analyte cations at a flow rate of $\sim 200$ 
$\mathrm{nL} / \mathrm{min}$. The 9.4 T FT-ICR MS was operated as follows. After 1 to $2 \mathrm{~s}$ accumulation and precursor ion selection in the external octopole ion trap, ions were transported by a radiofrequency octopole ion guide into an openended cylindrical ICR trap [17]. Gated ion trapping was used without cooling gas. For ECD experiments, a variable delay period (typically $50 \mathrm{~ms}$ at $10 \mathrm{~V}$ trapping voltage) was used to optimize ion magnetron motion phase [41]; a 3-mm-diameter electron beam (1-100 ms) was then injected into the ICR trap, followed by an electron clean-up event (100 ms) [40, 42]. The cathode potential during electron injection was $-5 \mathrm{~V}$ and kept at $+10 \mathrm{~V}$ otherwise. Accelerating grid voltage was at $+5 \mathrm{~V}$ during electron injection and at $-200 \mathrm{~V}$ otherwise. A multiple-pass electron injection regime was used (transfer octopole DC offset $-60 \mathrm{~V})[40,42]$. For AI-ECD experiments, precursor ions were activated by $\mathrm{CO}_{2} \mathrm{IR}$ laser irradiation (50-100 $\mathrm{ms}$ at $\sim 25 \mathrm{~W}$ continuous-wave laser output power; the laser was equipped with a $2.5 \times$ beam expander to improve overlap with the ion cloud) before electron injection [39]. ECD with post-activation of charge-reduced species was achieved with IR laser irradiation introduced after ECD and electron clean-up events [39]. Product ions were allowed to cool before frequency-sweep excitation followed by broadband detection. The time-domain transient signal was baseline corrected, Hanning apodized, zero-filled, and Fourier transformed to produce a magnitude-mode frequency spectrum that was converted to a mass-to-charge ratio spectrum by the quadrupolar approximation [43, 44]. Data acquisition was performed by use of a Predator data station [45] and data analysis with MIDAS 3.21 software. Experiments with the 12 T LTQ FT-ICR MS were done following standard ECD/AI-ECD technology described for similar instruments equipped with 7 and $12 \mathrm{~T}$ superconducting magnets [46, 47]. Raw transient time-domain data were recorded in addition to Fourier-transformed data to allow subsequent data analysis with both Xcalibur (Thermo Fisher Scientific) and MIDAS 3.21 software.

\section{ECD PIA Analysis}

The results are presented as ECD PIA of (corresponding to the most abundant isotopomer in each product ion isotopic cluster, which may include both radical and prime components) as a function of $\mathrm{N}-\mathrm{C}_{\alpha}$ bond or amino acid residue number. The number of the $\mathrm{N}-\mathrm{C}_{\alpha}$ bond corresponds to the number of the amino acid in a peptide sequence. Therefore, rupture of $\mathrm{N}-\mathrm{C}_{\alpha}$ bond number " $n$ " in peptide with " $m$ " amino acids may lead to formation of $c$-ions with number " $n-1$ " and $z$-ions with number " $m-n+1$." The abundance of Cterminal (z-type) ions is labeled according to the corresponding ruptured $\mathrm{N}-\mathrm{C}_{\alpha}$ bond number (counting from the N-terminus) and not in the order of standard $z$-ion numbering (counting from the C-terminus). In that way, the complementary pair of $c$ - and $z$-ions that correspond to a particular $\mathrm{N}-\mathrm{C}_{\alpha}$ bond cleavage may be overlaid for more direct comparison. The listed PIA for ECD ions is relative to the most abundant product ion in the corresponding $c$ - or $z$-ion series. Abundances of multiply charged product ions were divided by the corresponding number of charges to comply with the induced current method of ion detection in FT-ICR MS.

The amino acid hydrophobicity scale used throughout the study was originally devised to describe transmembrane domains in integral membrane proteins by Hessa et al. [48]. According to Hessa's hydrophobicity scale, hydrophobic amino acids have negative values and isoleucine is the most hydrophobic amino acid with an assigned apparent free energy $\Delta$ Gapp value of -0.6 $\mathrm{kcal} / \mathrm{mol}$ [48]. Polar (hydrophilic) amino acids are assigned positive values. The most polar amino acid is aspartic acid with $\Delta \mathrm{Gapp}=3.49 \mathrm{kcal} / \mathrm{mol}$ [48]. Several other amino acid hydrophobicity scales-such as Cornette [35], Kyte-Doolitle [49], transmembrane tendency scale [50] — differ slightly from the Hessa scale. Analysis of the major hydrophobicity scales confirms their applicability to describe a general trend of periodic distribution of hydrophobic and hydrophilic amino acids in amphipathic peptides and proteins.

\section{Results and Discussion}

\section{ECD of Triply Charged Amphipathic Peptides}

Wild-type M2 TMP (Ser-Ser-Asp-Pro-Leu-Val-Val-AlaAla-Ser-Ile-Ile-Gly-Ile-Leu-His-Leu-Ile-Leu-Trp-Ile-LeuAsp-Arg-Leu) is a transmembrane domain of the membrane protein M2 from influenza virus A [51]. Solutionphase and solid-state nuclear magnetic resonance (NMR) data strongly suggest an $\alpha$-helical structure $(\sim 3.6$ amino acids per turn, 5 turns in total, Protein Data Bank or PDB [52] entry 1NYJ) for M2 TMP, which is a fully functional proton channel [51]. ECD FT-ICR MS of M2 TMP demonstrates extensive sequence coverage by both $c$ - and $z$-type ions for triply protonated precursors (Figures 1 and 2, top). Only the $c_{24}$ product from ECD is doubly charged, indicating preferential charge neutralization at $\mathrm{His}_{16}$. Similar behavior was observed for a wide range of electron irradiation periods, from 100 to $1 \mathrm{~ms}$, as shown in Figure 1. Preferential ECD product ion formation arises from cleavages at $\mathrm{N}-\mathrm{C}_{\alpha}$ bond numbers $3,7,10,13,17,20,21$, and 24 for ECD of triply charged M2 TMP (Figures 1 and 2, top). Yields of $a$ - and $y$-ions follow a similar pattern, but are not considered here in view of their low abundances.

ECD and activated-ion (AI)-ECD of doubly and triply charged M2 TMP produce periodic distributions of product ions with the most abundant $z$-type ions located at the same backbone sites for both precursor charge states (Figure 2, top). Application of ECD to triply charged model amphipathic peptides, AA9 and LL9, is shown in Figure 3, and for a series of naturally occurring antimicrobial peptides of amphipathic nature, piscidins, in Figure 4 and Supplementary Figure S1, which can be found in the electronic version of this 


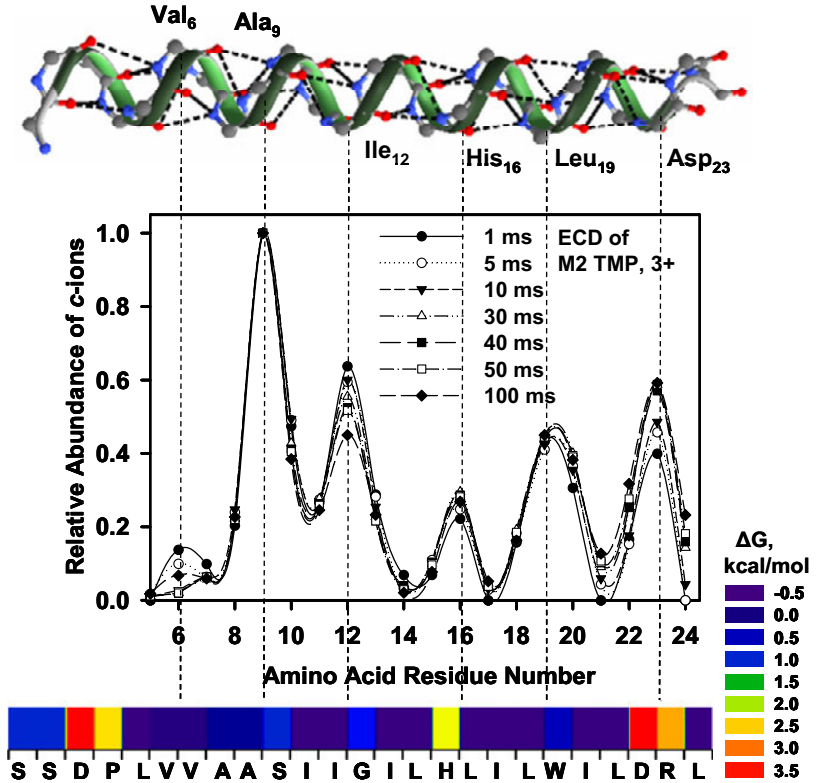

Figure 1. Middle: ECD FT-ICR MS relative product ion abundance (PIA) distributions ( $c$-ions) for triply protonated peptide M2 TMP as a function of amino acid residue number and electron irradiation period, demonstrating periodic sequence variation of PIA, reproducible over a wide range of electron irradiation periods (1-100 ms). Bottom: amino acid hydrophobicity distribution in M2 TMP, showing periodicity in hydrophobic and hydrophilic amino acid location (color-coding scale according to Hessa et al.: blue denotes the most hydrophobic). Top: solution-phase $\alpha$-helical structure of M2 TMP (PDB entry 1NYJ), demonstrating that periodicity in the ECD product ion distribution ( 3 or 4 amino acids per period) corresponds to that of an $\alpha$-helix ( 3.6 amino acids per turn).

article. The reproducibility of the results was confirmed by performing similar ECD experiments with a $14.5 \mathrm{~T}$ LTQ FT-ICR MS (National High Magnetic Field Laboratory [NHMFL], Tallahassee, FL, USA) [53], a 12 T LTQ FT-ICR MS (EPFL, Lausanne, Switzerland), a $9.4 \mathrm{~T}$ FT-ICR MS (NHMFL), a 9.4 T FT-ICR MS (Bruker Daltonics, Bremen, Germany), and a 7-T LTQ FT-ICR MS (Thermo Fisher Scientific, Bremen, Germany), described elsewhere [54, 55]. The periodic character (e.g. number and position of maxima) of ECD PIA for M2 TMP remains practically unchanged between different experimental setups. ECD PIA variation at each particular backbone cleavage site is consistent with reported ECD PIA reproducibility and repeatability for other peptides and does not exceed $10 \%$ on average [16].

\section{ECD of Doubly Charged Amphipathic Peptides}

ECD FT-ICR MS of doubly charged M2 TMP shows only a few product ions (Figure 2, top). As expected, more efficient fragmentation for vibrationally activated doubly charged precursors is obtained by activated ion ECD. Mainly $z$-type product ions and not $c$-ions are observed for ECD of doubly charged M2 TMP, supporting the expected preferential charge retention by $\mathrm{C}$ terminal Arg. Although less extensive, ECD of doubly charged precursor ions nevertheless clearly indicates periodic abundance variation for $z$-type ions attributed to cleavages mainly in the $\mathrm{N}$-terminal part of M2 TMP (Figure 2, top). Preferential product ion formation is the result of cleavages at $\mathrm{N}-\mathrm{C}_{\alpha}$ bond numbers $3,6(7), 10$, and 13 for ECD of doubly charged M2 TMP, in agreement with ECD of a triply charged peptide.

Similar general characteristics are observed for ECD of other amphipathic peptides. For instance, Figure 2 (bottom) shows the influence of vibrational preactivation on ECD of AA9 peptide. Ion activation before ECD with laser powers of 10 and $20 \mathrm{~W}$ produces similar fragmentation patterns. $\mathrm{N}$-terminal (c-ions) and C-terminal (z-ions) product ion distributions overlap in the middle of peptide
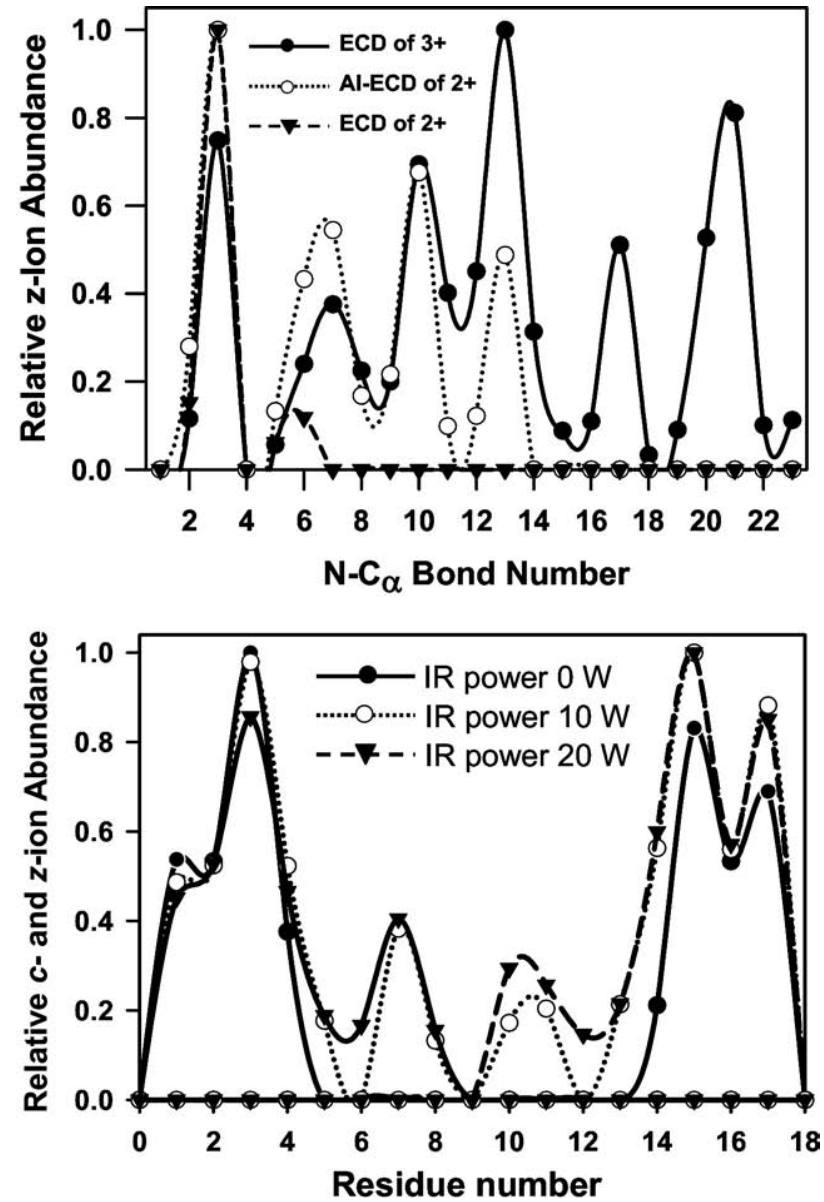

Figure 2. ECD and activated-ion (AI)-ECD FT-ICR MS relative PIA distribution for doubly protonated (top) transmembrane peptide M2 TMP (z-ions), and (bottom) amphipathic peptide AA9 (EAEKAAKEAEKAAKEAEK) ( $c$ - and $z$-ions), as a function of $\mathrm{N}-\mathrm{C}_{\alpha}$ bond number or amino acid residue number. Increased ion internal energy enhances formation of $\mathrm{N}$ - and $\mathrm{C}$-terminal product ions toward the middle of the peptides. Higher charge state (triply charged compared to doubly charged M2 TMP) induces effects similar to AI-ECD of doubly charged peptides (top), with PIA maxima at similar $\mathrm{N}-\mathrm{C}_{\alpha}$ bond numbers for ECD and AI-ECD of doubly and triply charged peptide. Note that $z$-ions are indexed according to the corresponding $\mathrm{N}-\mathrm{C}_{\alpha}$ bond number rupture, rather than conventional numbering from the C-terminus (see Experimental section). 

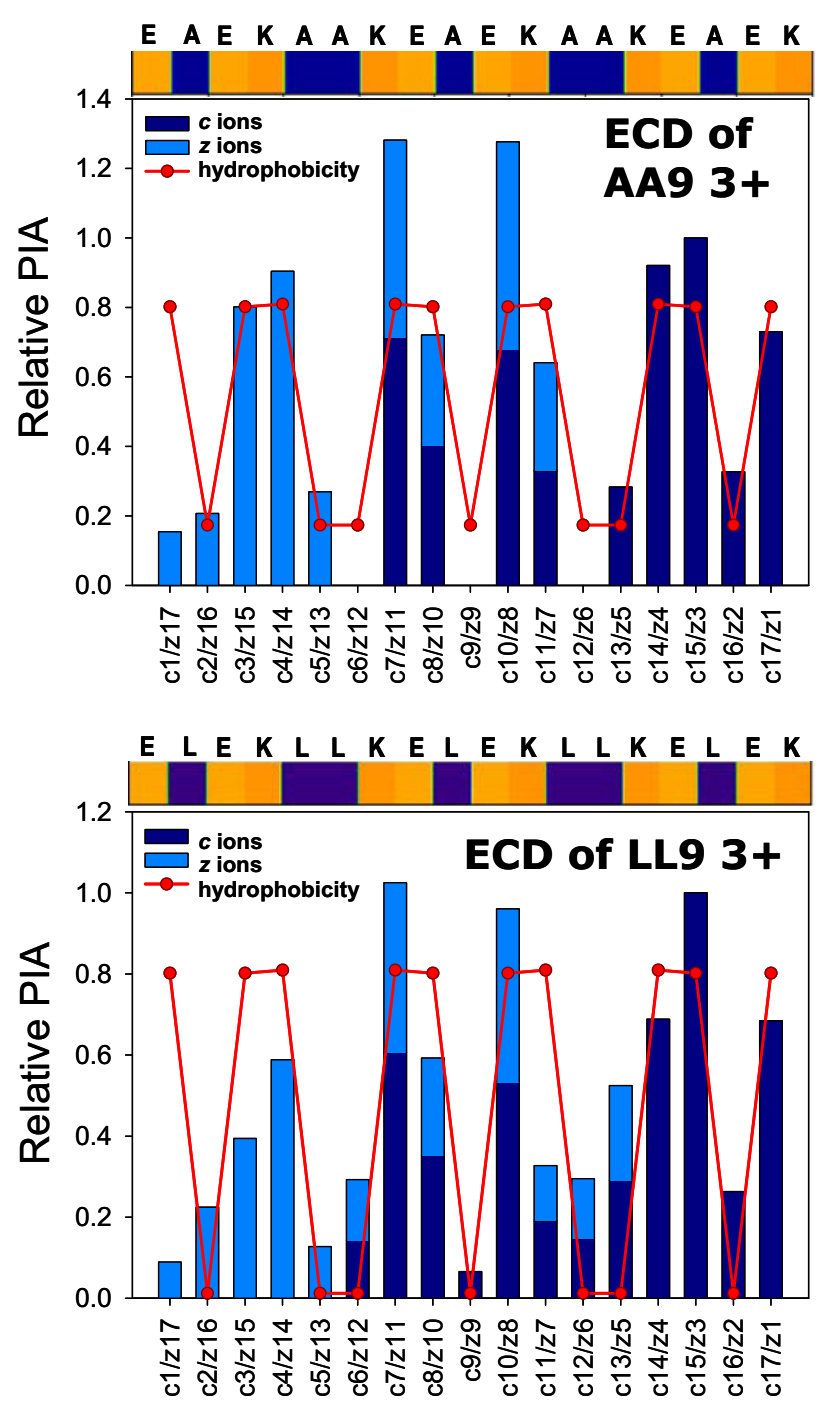

Figure 3. ECD FT-ICR MS relative PIA distribution for triply protonated amphipathic peptides (top) AA9 (EAEKAAKEAEKAAKEAEK) and (bottom) LL9 (ELEKLLKELEKLLKELEK) as a function of product ion number, demonstrating periodic PIA sequence variation. $\mathrm{N}$-terminal ( $c$-ions) and $\mathrm{C}$-terminal ( $z$-ions) PIA are separately scaled relative to the most abundant ion in each PIA distribution. The amphipathic nature of AA9 and LL9 is indicated by the sequence-periodic distribution of hydrophobic and hydrophilic amino acid residues shown (both above and included on the graph) and color-coded according to the Hessa hydrophobicity scale as in Figure 1.

sequence, at $\mathrm{N}-\mathrm{C}_{\alpha}$ bond number $\sim 9$, thus providing complete sequence coverage of the middle part of the peptide. Further increase of IR laser power or irradiation period does not lead to expansion of the extent of $c$ - or $z$-ion coverage, but induces a typical infrared multiphoton dissociation fragmentation pattern.

ECD FT-ICR MS of six doubly protonated horse myoglobin tryptic fragments ([1-16], [17-31], [32-42], [64-77], [103-118], and [119-133]) without precursor ion vibrational activation (Supplementary Figure S2) and with vibrational activation (Figure 5) confirm preferential and sometimes periodic product ion formation from peptides with mainly $\alpha$-helical or $\beta$-turn second- ary structure in solution (before protein digestion). Predominantly $z$-ions are observed because of preferential charge retention at the C-terminal Lys or Arg basic residue upon electron capture, as expected for doubly charged tryptic peptides. The AI-ECD product ion distribution exhibits more complete sequence coverage than ECD, with $c$-ions extending further toward the $\mathrm{N}$-terminus and $z$-ions further toward the C-terminus, as well as more extensive periodicity. A control experiment was performed by use of another enzyme, Asp- $\mathrm{N}$, that produces a different set of enzymatic fragments. Importantly, similar preferential ECD product ion formation was observed (for example, for myoglobin fragment [85-108]; data not shown).

Supplementary Figure S2 demonstrates preferential cleavage at the $\mathrm{N}-\mathrm{C}_{\alpha}$ bond number $4\left(z_{n-3}\right)$ for fragments with a distinct $\alpha$-helical or turn structure at the N-terminus (fragments [1-16], [17-31], [64-77], and [103-118]). For extended solution-phase $\alpha$-helical structures, a periodic ECD product ion distribution is observed (fragments [1-16], [64-77], and [103-118]). The periodicity is more pronounced in AI-ECD data (Figure 5), demonstrating a period of 3 amino acids for the specified myoglobin fragments.

The product ion distribution for myoglobin [119133] differs by the presence of a local maximum (cleavage at the $\mathrm{N}-\mathrm{C}_{\alpha}$ bond number 7) between two more global maxima $\left(\mathrm{N}-\mathrm{C}_{\alpha}\right.$ bond numbers 5 and 9$)$, more evident in AI-ECD. Interestingly, amino acid hydrophobicity distribution demonstrates a similar pattern in this sequence region. Furthermore, myoglobin fragment

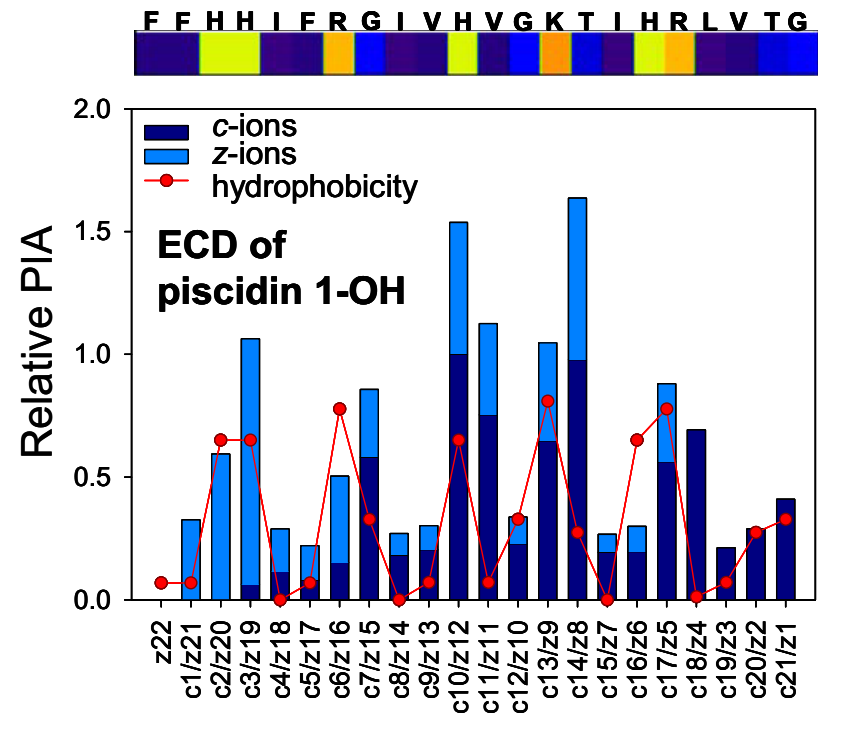

Figure 4. ECD FT-ICR MS relative PIA distribution for triply protonated amphipathic antimicrobial peptide piscidin 1 (FFHHIFRGIVHVGKTIHRLVTG) in free acid form as a function of product ion number. $\mathrm{N}$-terminal (c-ions) and $\mathrm{C}$-terminal ( $z$-ions) PIA are separately scaled relative to the most abundant ion in each PIA distribution. Labeling at the top of each panel is as in Figure 3. Data for piscidin 1 in amide form and for piscidin 3 in amide and free acid forms are shown in Supplementary Figure S1. 
[1-16]
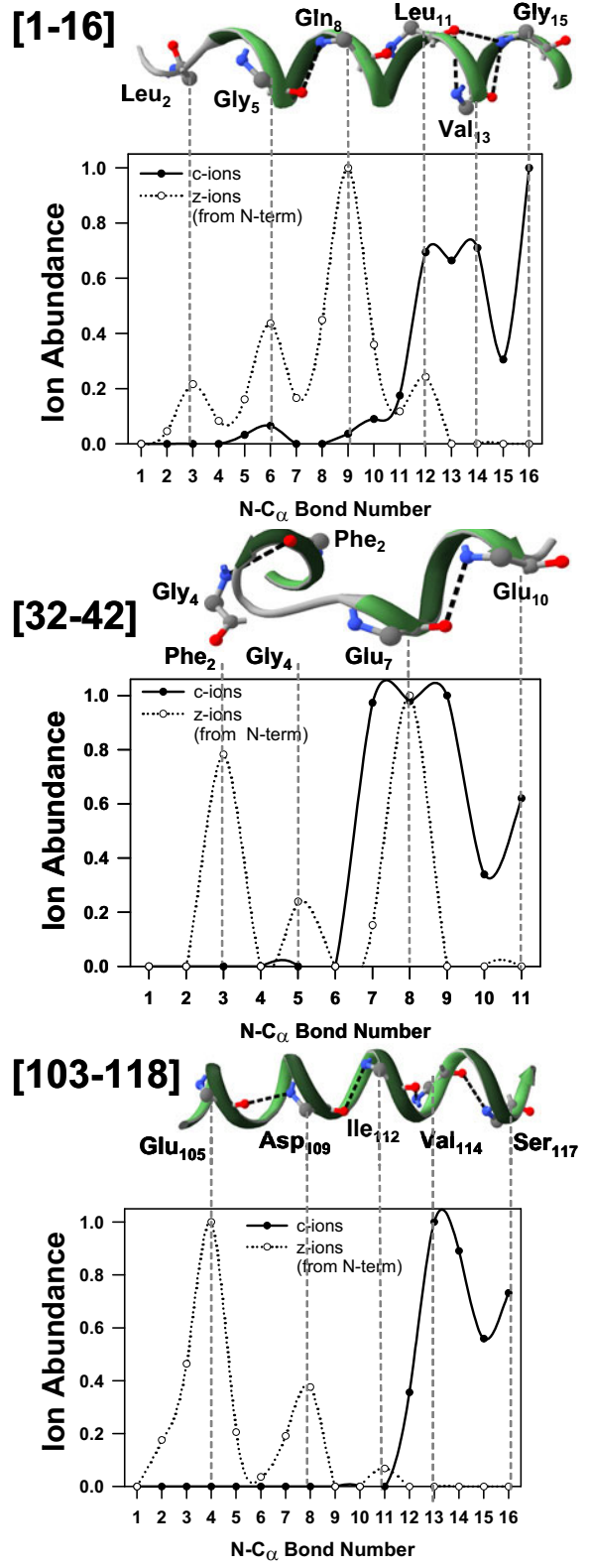

[17-31]
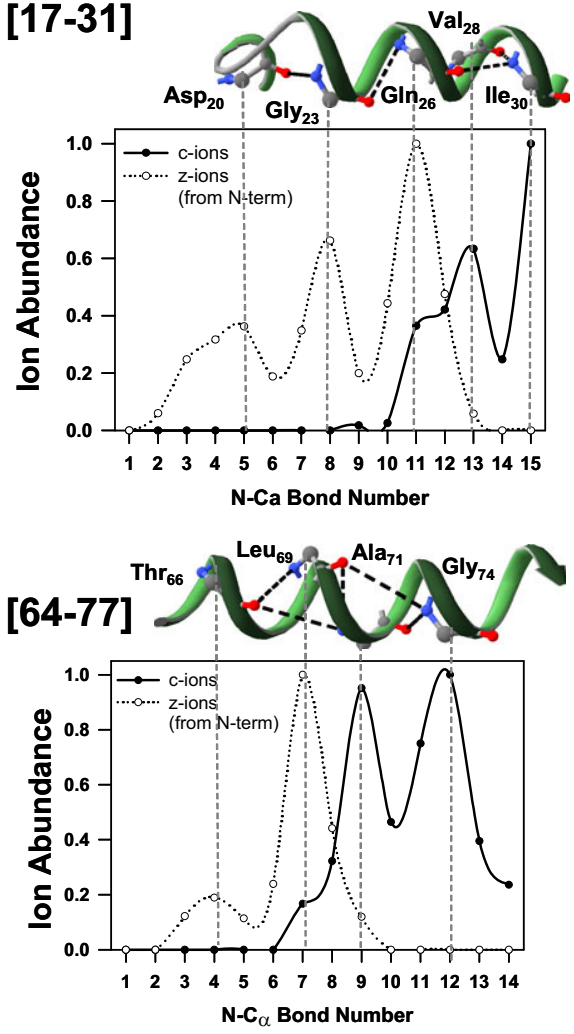

[119-133]

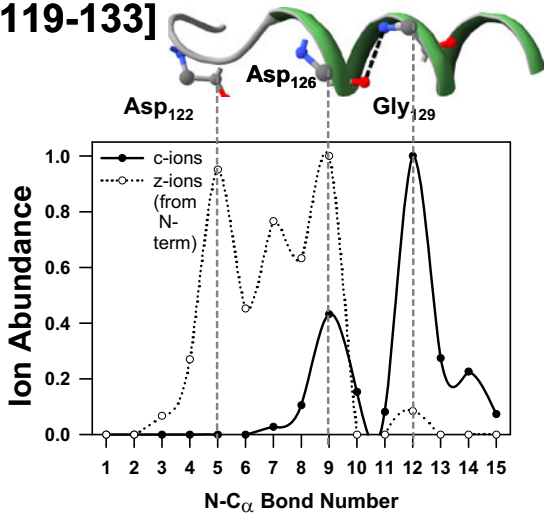

Figure 5. Activated ion ECD FT-ICR MS relative PIA distribution for bottom-up structural analysis of horse myoglobin, demonstrating preferential cleavages for doubly charged tryptic peptides and indicating ion internal energy influence on ECD fragmentation pattern (compared to Supplementary Figure S2). Labeling at the top of each panel is as in Figure 1. Solution phase structures of horse myoglobin tryptic fragments are drawn as in the intact protein, PDB entry 1WLA.

[64-77] differs from the others by location of a basic residue, His, at the $\mathrm{N}$-terminus (the $\mathrm{N}$-terminal proton can thus be shared between the N-terminal amide and basic residue), resulting in different gas-phase structures and competition in formation of $c$-type and $z$-type ions.

\section{Characteristic Features of ECD of Amphipathic Peptides}

In contrast to the PIA distribution for CID, product ion formation in ECD is believed to be nonspecific regard- ing the cleavage site, leading to much less pronounced variation of PIA in ECD than in CID. However, ECD of amphipathic peptides clearly demonstrates an order-ofmagnitude sequence modulation of PIA. Overall, periodic variation of hydrophobic and hydrophilic amino acids in the primary structure of amphipathic peptides leads to the following ECD characteristics: (1) periodic PIA sequence variation is reproducible over a wide range of ECD parameters and from different experimental platforms; (2) PIA local and global maxima are not necessarily located near the charged site; and (3) ion activation before ECD not only extends product ion 
sequence coverage but also preserves ion yield modulation.

The observed periodic modulation may be explained by existence of spatially distinct hydrophobic and hydrophilic regions in the amino acid sequence. Schematic representation (the so-called $\alpha$-helical net) of the idealized alpha helix shown in Scheme $\mathbf{1}$ allows visual identification of preferential ECD cleavage patterns.

A fragmentation map of the central part of M2 TMP, known from NMR to be $\alpha$-helical in solution and solid state, demonstrates preferential cleavages at the $\mathrm{N}$ terminal or C-terminal side of a single hydrogen spine, and a turning point near the His ${ }_{16}$ residue. Presumably, the Coulombic potential induced by protonation at $\mathrm{His}_{16}$ and $\mathrm{Arg}_{24}$ is responsible for this shift. Preferential fragmentation at the N-terminal side of $\mathrm{Arg}_{24}$ and $\mathrm{Asp}_{3}$ takes place outside of the $\alpha$-helical part of M2 TMP and indicates preferential product ion formation near hydrophilic residues (Asp and Arg are among the most hydrophilic residues according to Hessa's scale and others).

Following this approach, Scheme 2 shows preferential ECD product ion formation projected onto the idealized $\alpha$-helical net for myoglobin tryptic fragment [1-16].

Both ECD and AI-ECD clearly indicate preferential product ion yield ascribed to the cleavage N-terminal to the most polar residue in each $\alpha$-helical turn. Increased ion internal energy in AI-ECD may lead to the displacement of PIA maxima by one amino acid residue. The displacement in the central part of the $\alpha$-helix is toward a similarly hydrophilic amino acid. Preferential product ion yield shift toward a less hydrophilic amino acid in the N-terminal part of myoglobin [1-16] in AI-ECD is yet to be rationalized. The single amino acid resolution distribution of hydrophobicity along the peptide sequence in amphipathic peptides AA9 and LL9 (Figure 3) and antimicrobial peptides, piscidins (Figure 4 and

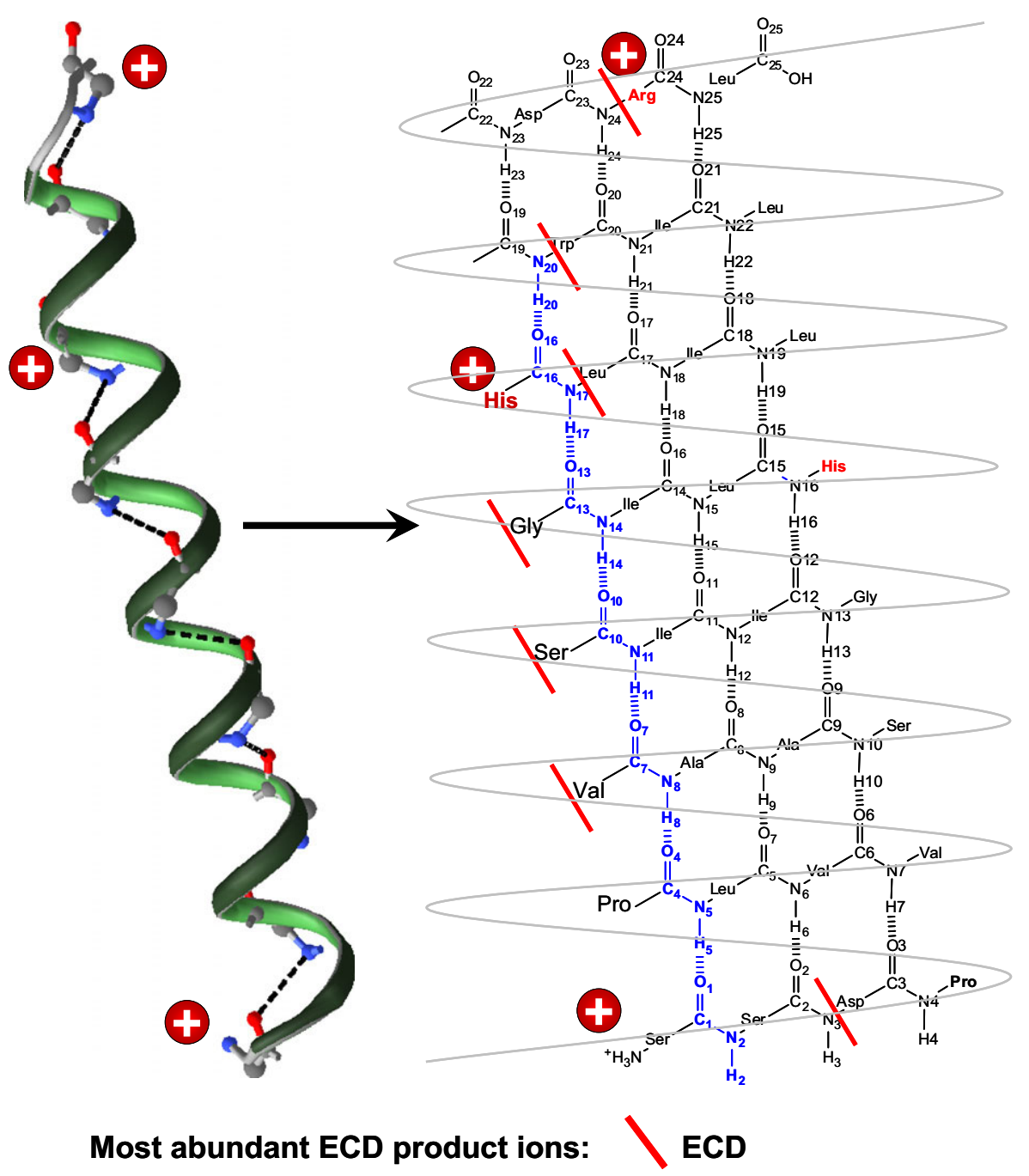

Scheme 1. Schematic representation of hydrogen-bonded network in peptide M2 TMP (PDB entry $1 \mathrm{NYJ}$ ) as an idealistic alpha helical net (a perfect $\alpha$-helix configuration with $3 \mathrm{H}$-spines). Preferential cleavage sites (the most abundant ECD product ions) of triply charged precursor M2 TMP ions are located on both sides of a single $\mathrm{H}$-spine. 


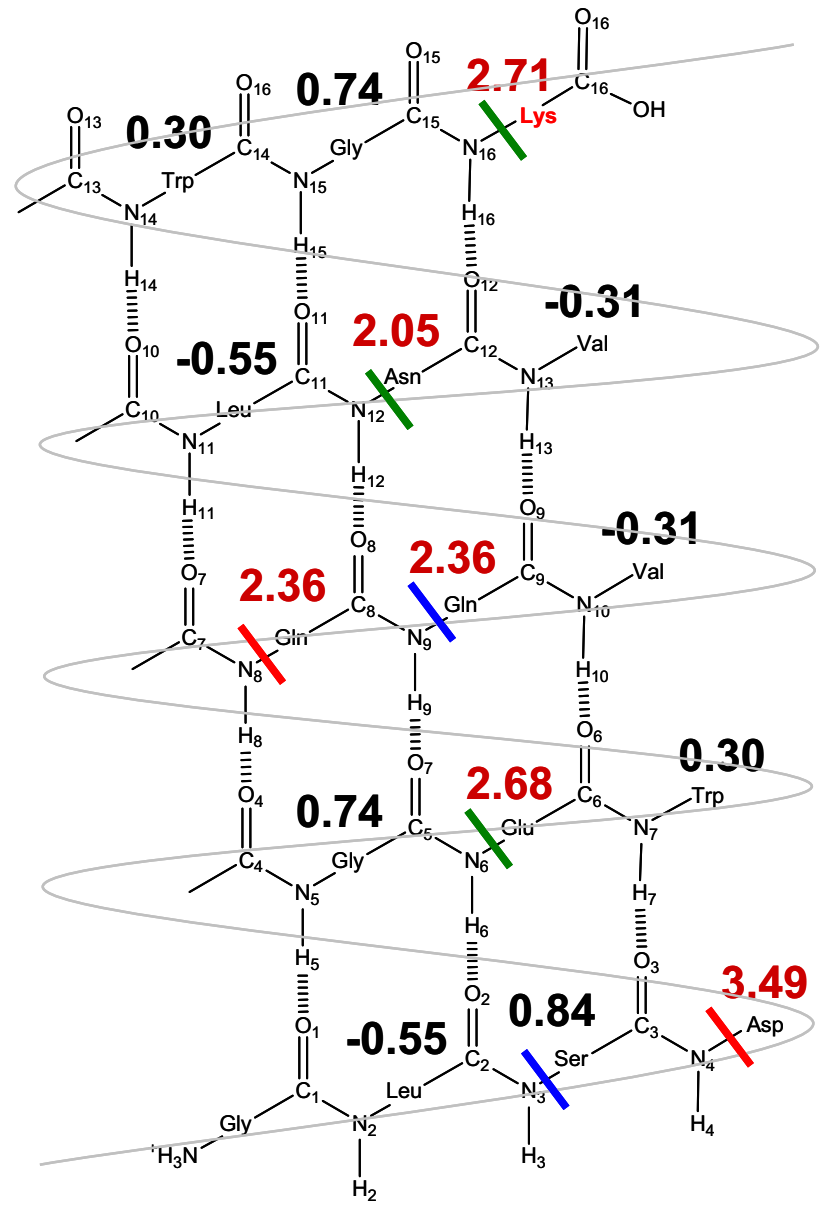

Most abundant ECD product ions:

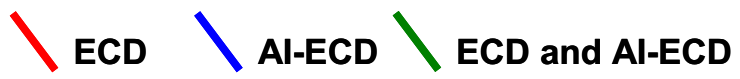

Scheme 2. Schematic representation of the hydrogen-bonded network in tryptic myoglobin fragment [1-16], that is known to have hydrophobic and polar faces, as an idealistic alpha helical net (a perfect $\alpha$-helix configuration with $3 \mathrm{H}$-spines). Preferential cleavage sites (the most abundant ECD and AI-ECD product ions) are located next to the most hydrophilic residues for the doubly charged precursor peptide.

Supplementary Figure S1), confirms these observations. The comparative analysis of ECD PIA periodic distributions and periodic variation of amino acid hydrophobicity in $\alpha$-helical M2 TMP reveals a general rough correlation between the number and location of maxima for triply (Figure 1, Figure 2, top) and doubly (Figure 2, top) charged M2 TMP (Figure 6). In good agreement with the locations of the most abundant product ions for ECD of triply charged M2 TMP, the polar amino acids along the peptide backbone in M2 TMP are residues $3,10,13,16,20,23$, and 24 . Preferential product ion formation at the $\mathrm{N}-\mathrm{C}_{\alpha}$ bonds 17 and 21 indicates a shift of a cleavage site by one residue toward the C-terminus.

Therefore, we can add the following characteristics of amphipathic peptide ECD: (1) the number and loca- tion of PIA maxima correlate with amino acid hydrophobicity maxima generally within a single amino acid displacement; and (2) preferential cleavage sites may be located near a selected hydrogen spine in an $\alpha$-helical segment of a peptide. Nevertheless, correlation of PIA in ECD performed in the gas phase with amino acid hydrophobicity values obtained for solution phase will require more detailed thermodynamic understanding of gas-phase "hydrophobicity."

\section{Sequence-Periodic ECD: Current Understanding}

Enhanced yield of ECD product ions within one $\alpha$ helical turn toward the $\mathrm{N}$-terminus from the protonated amino acid residue in proteins was observed by Breuker et al. [12] and rationalized through a keto-enol type tautomerism, as a result of partial charge-transfer along the hydrogen-bond network arising from the polarization of backbone amide groups by basic amino acid side chains. In the cited work and previous works of that group, correlation between ECD PIA and secondary $(\alpha$-helical) protein structure has been suggested. Nevertheless, earlier reported experimental results did not

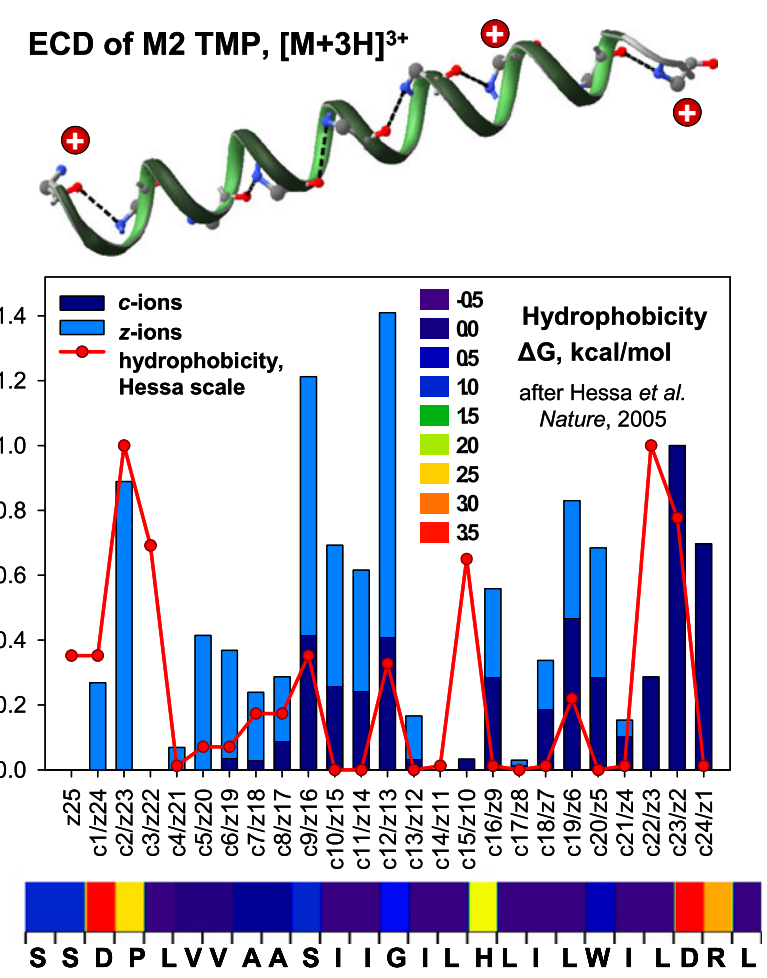

Figure 6. ECD FT-ICR MS relative PIA distribution (both $c$ - and $z$-ions) for triply protonated peptide M2 TMP as a function of $\mathrm{N}-\mathrm{C}_{\alpha}$ bond number, demonstrating periodic PIA sequence variation correlating with amino acid hydrophobicity distribution. Bottom: amino acid hydrophobicity distribution in M2 TMP, showing periodicity in hydrophobic and hydrophilic amino acid location (color-coding scale according to Hessa et al.). Top: solution-phase $\alpha$-helical structure of M2 TMP (PDB entry 1NYJ), demonstrating that periodicity of the ECD product ion distribution ( 3 or 4 amino acids per period) corresponds to that of an $\alpha$-helix (3.6 amino acids per turn). 
indicate several consecutive periods of ECD PIA and were not sufficient to deduce the characteristic features of amphipathic peptide ECD described here. Following hot hydrogen atom and related mechanisms of ECD suggested by McLafferty and colleagues, periodic ECD of amphipathic peptides arises from a set of specific preferential gas-phase conformations adopted by a biomolecular ion. ECD PIA is thus a function of proton solvation propensity at a given peptide backbone site. Nevertheless, understanding of the role of amino acid nature (e.g. hydrophobicity) in this mechanism remains unclear.

Charge-site-remote and enhanced fragmentation observed in ECD of amphipathic peptides can be rationalized within the framework of Tureček-Simons ECD mechanisms as a result of direct electron attachment to the $\sigma^{*}$ or, more probably, $\pi^{*}$ orbital of the backbone carbonyl groups at the corresponding sites along the peptide sequence. Periodic distribution of PIA in ECD would then be explained by the characteristic location of not only basic, presumably protonated, amino acids (e.g., $\mathrm{His}_{16}$ and $\mathrm{Arg}_{24}$ ), but also neutral amino acids (e.g., glycine) that can allow exothermic abstraction of an $\alpha$-proton toward the long-lived amide anion in an excited electronic state [56, 57]. In M2 TMP, a Gly residue is located in the middle of the peptide, at position 12, one $\alpha$-helix turn away from the basic $\mathrm{His}_{16}$ residue and therefore fulfilling the periodic requirement. Although the Tureček-Simons approach was implemented specifically to rationalize formation of ECD product ions at charge-remote sites, it does not directly explain the presently observed modulation of PIA and does not suggest a general correlation with amino acid properties, except for basic residues and Gly.

The important role of hydrogen bonds in biological systems on PIA in ECD has been particularly outlined in the ECD mechanism suggested by Zubarev and colleagues and based on direct electron capture to the neutral hydrogen bond of the $-\mathrm{N}-\mathrm{HO}=\mathrm{C}-$ group, such as in $\alpha$-helical and $\beta$-sheet peptide and protein structure units. Electron attachment leads to formation of an anionic site at the nitrogen atom and, at the same time, hydrogen atom transfer to the backbone carbonyl, initiating $\mathrm{N}-\mathrm{C}_{\alpha}$ bond rupture. The neutral hydrogen bond mechanism has been tested on a small model protein, Trp cage, and demonstrated the best-to-date correlation between the PIA in ECD and the propensity of a given carbonyl to form hydrogen bonds. In the event that hydrogen bonding is not available, electron capture will follow the Tureček-Simons mechanism described earlier. Although the H-bond description of the ECD process takes into account hydrogen bonds that form H-spines in $\alpha$-helical (amphipathic) peptides, periodic variation of PIA in ECD of amphipathic peptides is not readily apparent from this approach. The recent work of Williams and coworkers on ECD of hydrated tripeptides further supports the influence of hydrogen bonds on ECD [58]. They show that addition of water molecules and formation of new hydrogen bonds increases the probability for typical ECD ions of $c$ - and z-type to be formed instead of $b$-ions that presumably result from vibrational excitation of precursor cations [58].

\section{Periodic ECD: Influence of Hydrogen-Bonding Networks}

As an alternative to direct sequence-PIA correlation, the periodic ECD of amphipathic peptides may be influenced by the structure of their gas-phase hydrogenbonding networks. From that perspective, correlation of PIA in ECD with amino acid hydrophobicity may be considered as a result of hydrogen-bonding networks that involve nearest amino acids. Hydrogen bonds are stronger between hydrophilic residues compared to hydrophobic-hydrophobic and hydrophobichydrophilic pairs. Taking into account hydrogenbonding interactions between remote amino acids, such as between amino acids in the nearest turns of $\alpha$-helices, may drastically improve the observed correlation factor between hydrophobicity and ECD PIA and, simultaneously, indicate possible peptide and protein sitespecific (amino acid resolution) secondary structure organization (data not shown).

The preferential yield of product ions in ECD along a single (idealized) $\mathrm{H}$-spine of an amphipathic peptide may establish a link to quantum physics-based consideration of energy relaxation in $\alpha$-helical peptides, substantially developed in the last decade [59]. Energy relaxation dynamics that, according to the quantum physics models, involve a single $\mathrm{H}$-spine, may account not only for charge-site-remote and preferential fragmentation in ECD, but also indicate a qualitative role of hydrogen-bonding networks and a quantitative role of H-bond parameters (such as length, energy, or force constant) that are in turn determined by amino acid sequence in a given peptide or protein [60]. To a first approximation, amide-I relaxation dynamics is considered as an intermediate in the ECD process. Initial excitation of the amide-I mode is suggested to be attributed to peptide/protein rapid conformational change upon charge neutralization following electron capture. Subsequent decay of amide-I excitation along the hydrogen-bonded structure, as in an $\alpha$-helical peptide, was calculated to induce a local contraction of the peptide lattice that propagates along the selected $\mathrm{H}$ spine. Quantum physics models of amide-I relaxation in $\alpha$-helical peptides confirm excitation propagation along a selected $\mathrm{H}$-spine with only a minor excitation energy component diverted into other $\mathrm{H}$-spines. Selection of the H-spine follows the position of the initially excited site, such as the charge neutralization site in ECD. The finite size of a realistic $\alpha$-helical peptide results in reflection of a $\mathrm{H}$-bond deformation wave from the $\mathrm{N}$ and C-termini and leads to increased amplitude and lifetime of H-bond network contractions. Specific prop- 
erties of hydrogen bonds (such as H-bond force constant or energy) along the hydrogen-bonding network may trigger $\mathrm{H}$ atom transfer to the carbonyl oxygen and lead to formation of a carbonyl radical. Subsequent cleavage of the nearby $\mathrm{N}-\mathrm{C}_{\alpha}$ bond may proceed in agreement with the known ECD mechanisms. Therefore, the amide-I relaxation may explain the specific attachment of a hydrogen atom to a carbonyl oxygen remote from the charge neutralization site. This mechanism agrees with the enol-to-keto tautomerism mechanism for preferential cleavage in ECD suggested by Breuker et al. [12] and provides an analytical description of the process.

\section{Conclusions}

An unmistakable extended periodic variation of ECD PIA along the peptide sequence, with an average period between 3 and 4 amino acids for the transmembrane domain of M2 protein from influenza virus A (M2 TMP), with suggested solution-phase $\alpha$-helical secondary structure (3.6 amino acids per turn), is demonstrated. Analysis of the fragmentation patterns suggests periodic modulation of PIA as a result of the amphipathic nature of the M2 TMP peptide. The observation of periodic PIA behavior was further confirmed by ECD of model amphipathic peptides, antimicrobial peptides of amphipathic nature, and enzymatic fragments of primarily $\alpha$-helical protein, myoglobin. The tenfold modulation of PIA amplitude for ECD of amphipathic peptides reveals the specific nature of ECD in contrast to previously reported nonspecific and random behavior in regard to the cleavage between different amino acids. Based on the obtained experimental data the characteristic features for ECD of amphipathic peptides were indicated. Mapping of preferential cleavage sites on the 2D idealistic $\alpha$-helical nets suggests enhanced yield along the hydrogen-bonding networkmediated pathway that connects the charged sites and most hydrophilic residues in each turn, thus revealing most efficient ECD at $\mathrm{N}-\mathrm{C}_{\alpha}$ bonds located at the $\mathrm{N}$-terminal and C-terminal sides of a selected $\mathrm{H}$-spine. The observed dependences support previous reports on the general influence of hydrogen bonds and distribution of basic residues on ECD fragmentation patterns [58]. Current ECD mechanisms can explain some of the experimentally observed features, whereas new insights described here as a set of rules in ECD of amphipathic peptides may advance further ECD mechanism development [60].

\section{Acknowledgments}

The authors thank Eduard Chekmenev and Conggang Li from Dr. Timothy A. Cross's group (NMR Program, NHMFL, Tallahassee, FL) and Myriam Cotten for providing samples. Vincent Pouthier, Ron Heeren, Konstantin Zhurov, and Eduard Chekmenev are gratefully acknowledged for encouraging discussions and comments on the manuscript. This work was supported by EPFL, NSF
Division of Materials Research through DMR-0654118 and the State of Florida. We are indebted to Bruker Daltonics and Thermo Fisher Scientific (both Bremen, Germany) for providing manufacturing facilities-based FT-ICR mass spectrometers to confirm results obtained in our research laboratories.

\section{Appendix Supplementary Material}

Supplementary material associated with this article may be found in the online version at doi: $10.1016 / \mathrm{j}$. jasms.2009.02.015.

\section{References}

1. Zubarev, R. A.; Kelleher, N. L.; McLafferty, F. W. Electron Capture Dissociation of Multiply Charged Protein Cations. A Nonergodic Process. J. Am. Chem. Soc. 1998, 120, 3265-3266.

2. Zubarev, R. A. Reactions of Polypeptide Ions with Electrons in the Gas Phase. Mass Spectrom. Rev. 2003, 22, 57-77.

3. Zubarev, R. A. Electron Capture Dissociation and Other Ion-Electron Fragmentation Reactions. In Principles of Mass Spectrometry Applied to Biomolecules, Lifshitz, C.; Laskin, J., Eds. John Wiley and Sons: Hoboken, NJ, 2006; pp 475-518.

4. Syka, J. E. P.; Coon, J. J.; Schroeder, M. J.; Shabanowitz, J.; Hunt, D. F. Peptide and Protein Sequence Analysis by Electron Transfer Dissociation Mass Spectrometry. Proc. Natl. Acad. Sci. U. S. A. 2004, 101, 9528-9533.

5. Coon, J. J.; Ueberheide, B.; Syka, J. E. P.; Dryhurst, D. D.; Ausio, J.; Shabanowitz, J.; Hunt, D. F. Protein Identification Using Sequential Ion/Ion Reactions and Tandem Mass Spectrometry. Proc. Natl. Acad. Sci. U. S. A. 2005, 102,9463-9468.

6. Palmblad, M.; Tsybin, Y. O.; Ramstrom, M.; Bergquist, J.; Hakansson, P. Liquid Chromatography and Electron-Capture Dissociation in Fourier Transform Ion Cyclotron Resonance Mass Spectrometry. Rapid Commun. Mass Spectrom. 2002, 16, 988-992.

7. Savitski, M. M.; Nielsen, M. L.; Kjeldsen, F.; Zubarev, R. A. ProteomicsGrade De Novo Sequencing Approach. J. Proteome Res. 2005, 4, 2348 2354.

8. Adams, C. M.; Kjeldsen, F.; Zubarev, R. A.; Budnik, B. A.; Haselmann, K. F. Electron Capture Dissociation Distinguishes a Single D-Amino Acid in a Protein and Probes the Tertiary Structure. I. Am. Soc. Mass Spectrom. 2004, 15, 1087-1098.

9. Savitski, M. M.; Nielsen, M. L.; Zubarev, R. A. ModifiComb, a New Proteomic Tool for Mapping Substoichiometric Post-Translational Modifications, Finding Novel Types of Modifications, and Fingerprinting Complex Protein Mixtures. Mol. Cell. Proteomics 2006, 5, 935-948.

10. Meng, F. Y.; Forbes, A. J.; Miller, L. M.; Kelleher, N. L. Detection and Localization of Protein Modifications by High Resolution Tandem Mass Spectrometry. Mass Spectrom. Rev. 2005, 24, 126-134.

11. Kelleher, N. L. Top-Down Proteomics. Anal. Chem. 2004, 76, 196A-203A

12. Breuker, K.; Oh, H. B.; Lin, C.; Carpenter, B. K.; McLafferty, F. W. Nonergodic and Conformational Control of the Electron Capture Dissociation of Protein Cations. Proc. Natl. Acad. Sci. U. S. A. 2004, 101, 14011-14016.

13. Polfer, N. C.; Haselmann, K. F.; Langridge-Smith, P. R. R.; Barran, P. E Structural Investigation of Naturally Occurring Peptides by Electron Capture Dissociation and AMBER Force Field Modelling. Mol. Physics 2005, 103, 1481-1489.

14. Coon, J. J.; Syka, J. E. P.; Shabanowitz, J.; Hunt, D. F. Tandem Mass Spectrometry for Peptide and Protein Sequence Analysis. Biotechniques 2005, 38, 519-523.

15. Mikesh, L. M.; Ueberheide, B.; Chi, A.; Coon, J. J.; Syka, J. E. P.; Shabanowitz, J.; Hunt, D. F. The Utility of ETD Mass Spectrometry in Proteomic Analysis. Biochim. Biophys. Acta Proteins Proteomics 2006, 1764, 1811-1822.

16. Budnik, B. A.; Nielsen, M. L.; Olsen, J. V.; Haselmann, K. F.; Horth, P. Haehnel, W.; Zubarev, R. A. Can Relative Cleavage Frequencies in Peptides Provide Additional Sequence Information? Int. J. Mass Spectrom. 2002, 219, 283-294.

17. Tsybin, Y. O.; Haselmann, K. F.; Emmett, M. R.; Hendrickson, C. L. Marshall, A. G. Charge Location Directs Electron Capture Dissociation of Peptide Dications. J. Am. Soc. Mass Spectrom. 2006, 17, 1704-1711.

18. Iavarone, A. T.; Paech, K.; Williams, E. R. Effects of Charge State and Cationizing Agent on the Electron Capture Dissociation of a Peptide. Anal. Chem. 2004, 76, 2231-2238.

19. McAlister, G. C.; Berggren, W. T.; Griep-Raming, J.; Horning, S.; Makarov, A.; Phanstiel, D.; Stafford, G.; Swaney, D. L.; Syka, J. E. P.; Zabrouskov, V.; Coon, J. J. A Proteomics Grade Electron Transfer Dissociation-Enabled Hybrid Linear Ion Trap-Orbitrap Mass Spectrometer. J. Proteome Res. 2008, 7, 3127-3136. 
20. Pesavento, J. J.; Mizzen, C. A.; Kelleher, N. L. Quantitative Analysis of Modified Proteins and Their Positional Isomers by Tandem Mass Spectrometry: Human Histone H4. Anal. Chem. 2006, 78, 4271-4280.

21. Patriksson, A.; Adams, C.; Kjeldsen, F.; Raber, J.; van der Spoel, D.; Zubarev, R. A. Prediction of N-C-Alpha Bond Cleavage Frequencies in Electron Capture Dissociation of Trp-Cage Dications by Force-Field Molecular Dynamics Simulations. Int. J. Mass Spectrom. 2006, 248, 124-135.

22. Savitski, M. M.; Kjeldsen, F.; Nielsen, M. L.; Zubarev, R. A. Hydrogen Rearrangement to and from Radical $z$ Fragments in Electron Capture Dissociation of Peptides. J. Am. Soc. Mass Spectrom. 2007, 18, 113-120.

23. Lin, C. Cournoyer, J. C.; O'Connor, P. B. Use of a Double Resonance Electron Capture Dissociation Experiment to Probe Fragment Intermediate Lifetimes. J. Am. Soc. Mass Spectrom. 2006, 17, 1605-1615.

24. Mihalca, R.; Kleinnijenhuis, A. J.; McDonnell, L. A.; Heck, A. J. R.; Heeren, R. M. A. Electron Capture Dissociation at Low Temperatures Reveals Selective Dissociations. I. Am. Soc. Mass Spectrom. 2004, 15, 1869-1873.

25. Chakraborty, T.; Holm, A. I. S.; Hvelplund, P.; Nielsen, S. B.; Poully, J. C.; Worm, E. S.; Williams, E. R. On the Survival of Peptide Cations after Electron Capture: Role of Internal Hydrogen Bonding and Microsolvation. I. Am. Soc. Mass Spectrom. 2006, 17, 1675-1680.

26. Breuker, K.; Oh, H. B.; Horn, D. M.; Cerda, B. A.; McLafferty, F. W. Detailed Unfolding and Folding of Gaseous Ubiquitin Ions Characterized by Electron Capture Dissociation. J. Am. Chem. Soc. 2002, 124, 6407-6420.

27. Jarrold, M. F. Helices and Sheets In Vacuo. Phys. Chem. Chem. Phys. 2007, 9, 1659-1671.

28. Zilch, L. W.; Kaleta, D. T.; Kohtani, M.; Krishnan, R.; Jarrold, M. F. Folding and Unfolding of Helix-Turn-Helix Motifs in the Gas Phase. J. Am. Soc. Mass Spectrom. 2007, 18, 1239-1248.

29. Counterman, A. E.; Clemmer, D. E. Gas Phase Polyalanine: Assessment of $\mathrm{i} \rightarrow \mathrm{i}+3$ and $\mathrm{i} \rightarrow \mathrm{i}+4$ Helical Turns in $[\mathrm{Ala}(\mathrm{n})+4 \mathrm{H}](4+)(\mathrm{n}=$ 29-49) Ion. J. Phys. Chem. B 2002, 106, 12045-12051.

30. Oomens, J.; Polfer, N.; Moore, D. T.; van der Meer, L.; Marshall, A. G.; Eyler, J. R. Meijer, G.; von Helden, G. Charge-State Resolved MidInfrared Spectroscopy of a Gas-Phase Protein. Phys. Chem. Chem. Phys. 2005, 7, 1345-1348.

31. Stearns, J. A.; Boyarkin, O. V.; Rizzo, T. R. Spectroscopic Signatures of Gas-Phase Helices: Ac-Phe-(Ala)(5)-Lys-H+ and Ac-Phe-(Ala)(10)-LysH+. J. Am. Chem. Soc. 2007, 129, 13820-13821.

32. Zhang Z. Q. Bordas-Nagy, J. Peptide Conformation in Gas Phase Probed by Collision-Induced Dissociation and Its Correlation to Conformation in Condensed Phases. J. Am. Soc. Mass Spectrom. 2006, 17, 786-794.

33. Savitski, M. M.; Kjeldsen, F.; Nielsen, M. L.; Garbuzynskiy, S. O. Galzitskaya, O. V.; Surin, A. K.; Zubarev, R. A. Backbone Carbonyl Group Basicities Are Related to Gas-Phase Fragmentation of Peptides and Protein Folding. Angew. Chem. Int. Ed. 2007, 46, 1481-1484.

34. Chou, P. Y.; Fasman, G. D. Empirical Predictions of Protein Conformation. Annu. Rev. Biochem. 1978, 47, 251-276.

35. Cornette, J. L.; Cease, K. B.; Margalit, H.; Spouge, J. L.; Berzofsky, J. A.; Delisi, C. Hydrophobicity Scales and Computational Techniques for Detecting Amphipathic Structures in Proteins. J. Mol. Biol. 1987, 195, 659-685.

36. Ben Hamidane, H.; Chiappe, D.; Hartmer, R.; Vorobyev, A.; Moniatte, M. Tsybin, Y. O. Electron Capture and Transfer Dissociation: Peptide Structure Analysis at Different Ion Internal Energy Levels. J. Am. Soc. Mass Spectrom. 2008, doi:10.1016/j.jasms.2008.11.016

37. Gross, M. L.; Caprioli, R. M. The Encyclopedia of Mass Spectrometry. Biological Applications. Elsevier: Amsterdam, 2005; Vol. 2, p 435.

38. Senko, M. W.: Hendrickson, C. L.; Pasa-Tolic, L.; Marto, J. A.; White, F. M.; Guan, S.; Marshall, A. G. Electrospray Ionization FT-ICR Mass Spectrometry at 9.4 Tesla. Rapid Commun. Mass Spectrom. 1996, 10, $1824-1828$.

39. Hakansson, K.; Chalmers, M. J.; Quinn, J. P.; McFarland, M. A.; Hendrickson, C. L.; Marshall, A. G. Combined Electron Capture and Infrared Multiphoton Dissociation for Multistage MS/MS in a Fourier Transform Ion Cyclotron Resonance Mass Spectrometer. Anal. Chem. 2003, 75, 3256-3262.

40. Tsybin, Y. O.; Quinn, J. P.; Tsybin, O. Y.; Hendrickson, C. L.; Marshall, A. G. Electron Capture Dissociation Implementation Progress in Fourier Transform Ion Cyclotron Resonance Mass Spectrometry. J. Am. Soc. Mass Spectrom. 2008, 19, 762-771.
41. Tsybin, Y. O.; Hendrickson, C. L.; Beu, S. C.; Marshall, A. G. Impact of Ion Magnetron Motion on Electron Capture Dissociation Fourier Transform Ion Cyclotron Resonance Mass Spectrometry. Int. J. Mass Spectrom. 2006, 255, 144-149.

42. McFarland, M. A.; Chalmers, M. J.; Quinn, J. P.; Hendrickson, C. L. Marshall, A. G. Evaluation and Optimization of Electron Capture Dissociation Efficiency in Fourier Transform Ion Cyclotron Resonance Mass Spectrometry. J. Am. Soc. Mass Spectrom. 2005, 16, 1060-1066.

43. Ledford, E. B., Jr.; Rempel, D. L.; Gross, M. L. Space Charge Effects in Fourier Transform Mass Spectrometry Mass Calibration. Anal. Chem. $1984,56,2744-2748$.

44. Shi, S. D. H.; Drader, J. J.; Freitas, M. A.; Hendrickson, C. L.; Marshall, A. G. Comparison and Interconversion of the Two Most Common Frequency-to-Mass Calibration Functions for Fourier Transform Ion Cyclotron Resonance Mass Spectrometry. Int. J. Mass Spectrom. 2000, $196,591-598$

45. Blakney, G. T., Robinson, D. E., Ngan, V. L., Kelleher, N. L., Hendrickson, C. L., Marshall, A. G. In Proceedings of the 53rd ASMS Conference on Mass Spectrometry and Allied Topics, San Antonio, TX, June 5-9, 2005.

46. Cooper, H. J.; Akbarzadeh, S.; Heath, J. K.; Zeller, M. Data-Dependent Electron Capture Dissociation FT-ICR Mass Spectrometry for Proteomic Analyses. J. Proteome Res. 2005, 4, 1538-1544.

47. Parks, B. A.; Jiang, L. Thomas, P. M. Wenger, C. D.; Roth, M. J.; Boyne, M. T.; Burke, P. V.; Kwast, K. E.; Kelleher, N. L. Top-Down Proteomics on a Chromatographic Timescale Using Linear Ion Trap Fourier Transform Hybrid Mass Spectrometers. Anal. Chem. 2007, 79, 7984-7991.

48. Hessa, T.; Kim, H.; Bihlmaier, K.; Lundin, C.; Boekel, J.; Andersson, H.; Nilsson, I.; White, S. H.; von Heijne, G. Recognition of Transmembrane Helices by the Endoplasmic Reticulum Translocon. Nature 2005, 433, 377-381.

49. Kyte, J.; Doolittle, R. F. A Simple Method for Displaying the Hydropathic Character of a Protein. I. Mol. Biol. 1982, 157, 105-132.

50. Zhao, G.; London, E. An Amino Acid "Transmembrane Tendency" Scale That Approaches the Theoretical Limit to Accuracy for Prediction of Transmembrane Helices: Relationship to Biological Hydrophobicity. Protein Sci. 2006, 15, 1987-2001.

51. Kovacs, F. A.; Denny, J. K.; Song, Z.; Quine, J. R.; Cross, T. A. Helix Tilt of the M2 Transmembrane Peptide from Influenza A Virus: An Intrinsic Property. J. Mol. Biol. 2000, 295, 117-125.

52. Berman, H. M.; Westbrook, J.; Feng, Z.; Gilliland, G.; Bhat, T. N. Weissig, H.; Shindyalov, I. N.; Bourne, P. E. The Protein Data Bank. Nucleic Acids Res. 2000, 28, 235-242.

53. Schaub, T. M.; Hendrickson, C. L.; Horning, S.; Quinn, J. P.; Senko, M. W.; Marshall, A. G. High-Performance Mass Spectrometry: Fourier Transform Ion Cyclotron Rresonance at 14.5 Tesla. Anal. Chem. 2008, 80 3985-3990.

54. Syka, J. E. P.; Marto, J. A.; Bai, D. L.; Horning, S.; Senko, M. W.; Schwartz, J. C.; Ueberheide, B.; Garcia, B.; Busby, S.; Muratore, T.; Shabanowitz, J.; Hunt, D. F. Novel Linear Quadrupole Ion Trap/FT Mass Spectrometer: Performance Characterization and Use in the Comparative Analysis of Histone H3 Post-Translational Modifications. J. Proteome Res. 2004, 3, 621-626.

55. Tsybin, Y O; Witt, M. Baykut, G. Kjeldsen, F. Hakansson, P. Combined Infrared Multiphoton Dissociation and Electron Capture Dissociation with a Hollow Electron Beam in Fourier Transform Ion Cyclotron Resonance Mass Spectrometry. Rapid Commun. Mass Spectrom. 2003, 17, 1759-1768.

56. Syrstad, E. A.; Tureček, F. Toward a General Mechanism of Electron Capture Dissociation. J. Am. Soc. Mass Spectrom. 2005, 16, 208-224.

57. Sobczyk, M.; Anusiewicz, W.; Berdys-Kochanska, J.; Sawicka, A.; Skurski, P.; Simons, J. Coulomb-Assisted Dissociative Electron Attachment: Application to a Model Peptide. J. Phys. Chem. A 2005, 109, 250-258.

58. Prell, J. S.; O’Brien, J. T.; Holm, A. I. S.; Leib, R. D.; Donald, W. A.; Williams, E. R. Electron Capture by a Hydrated Gaseous Peptide: Effects of Water on Fragmentation and Molecular Survival. J. Am. Chem. Soc. 2008, 130, 12680-12689.

59. Falvo, C.; Pouthier, V. Vibron-Polaron in Alpha-Helices. I. SingleVibron States. J. Chem. Phys. 2005, 123, 184709.

60. Pouthier, V.; Tsybin, Y. O. Amide-I Relaxation-Induced Hydrogen Bond Distortion: An Intermediate in Electron Capture Dissociation Mass Spectrometry of Alpha-Helical Peptides? J. Chem. Phys. 2008, 129, 095106. 